\title{
FINAL ADULT HEIGHT IN PRECOCIOUS PUBERTY AND EARLY PUBERTY GIRLS TREATED WITH GNRH AGONISTS
}

\section{S. Wacharasindhu}

Department of Pediatrics, Faculty of Medicine, Chulalongkorn University, Bangkok, Thailand

Background: Precocious puberty is defined in girls who have puberty sign before the age of eight years. GnRH agonists can delay the bone age advancement and subsequently improve the final adult height.

Method: Sixty eight girls with central precocious puberty and early puberty with a mean age of $9 \pm 1.2$ years were treated with GnRH agonist $3.75 \mathrm{mg}$ intramuscular monthly for a mean period of $1.9 \pm 0.6 \mathrm{yr}$. Thelarche occurred at a mean age of $7.6 \pm 1.0 \mathrm{yr}$. Twenty eight girls ( $41 \%$ ) already had menarche before seeking medical advice.

Results: Predicted adult height $(\mathrm{PAH})$ before treatment was significantly lower than mid-parental height $(\mathrm{MPH})(151.6 \pm 6.7 \mathrm{vs} 155.4 \pm 3.9 \mathrm{~cm}, \mathrm{p}=0.003)$. After treatment, they reached their final adult heights $(\mathrm{FH})$ at a mean age of $14.6 \pm 1.3 \mathrm{yr}$. GnRH agonist can significantly improve $\mathrm{FH}$ compared to $\mathrm{PAH}$ before treatment $(156.7 \pm 5.1$ vs $151.6 \pm 6.7 \mathrm{~cm}, \mathrm{p}<0.001)$. Thirteen girls $(19 \%)$ had breast onset just after eight years of age which was classified as early puberty (EP). Treatment with GnHR agonist still improved FH of $157.9 \pm 5.6 \mathrm{~cm}$, compared to PAH before treatment of $153.2 \pm 7.5 \mathrm{~cm}(\mathrm{p}=0.04)$. However, GnRH agonist treatment in girls with bone age of more than $12.5 \mathrm{yr}$ cannot significantly improve FH. FH correlated well with MPH.

Conclusion: GnRH agonist significantly improves final adult height in precocious puberty and early puberty girls with bone age of less than $12.5 \mathrm{yr}$. 